Supplement of Atmos. Chem. Phys., 16, 1761-1771, 2016

http://www.atmos-chem-phys.net/16/1761/2016/

doi:10.5194/acp-16-1761-2016-supplement

(C) Author(s) 2016. CC Attribution 3.0 License.

(c) (i)

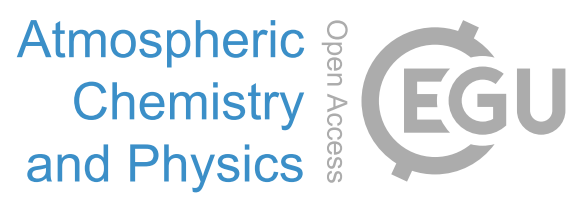

Supplement of

\title{
Hydroxyl radicals from secondary organic aerosol decomposition in water
}

H. Tong et al.

Correspondence to: Manabu Shiraiwa (m.shiraiwa@mpic.de)

The copyright of individual parts of the supplement might differ from the CC-BY 3.0 licence. 


\section{EPR experiments}

The spin counting method was applied for quantification of $\mathrm{OH}$ radicals using the embedded subroutine of the Bruker Xenon software (Weber, 2012). Briefly, peaks and a baseline of spectra were selected, followed by double integration of the peak intensity. Spin concentrations were calculated through the following equation (Eaton et al., 2010):

$$
\mathrm{DI}=\mathrm{c} \cdot\left[G_{R} \cdot C_{t} \cdot \mathrm{n}\right] \cdot\left[\frac{\sqrt{P} \cdot B_{m} \cdot Q \cdot n_{B} \cdot S \cdot(S+1) \cdot n_{S}}{f\left(B_{1}, B_{m}\right)}\right]
$$

where $c=$ constant determined by a standard sample with known number of spins, $G_{\mathrm{R}}=$ Receiver gain, $C_{\mathrm{t}}=$ Conversion time, $n=$ Number of scans, $P=$ Microwave power $(\mathrm{W}), B_{\mathrm{m}}=$ Modulation amplitude (Gauss), $Q=$ Quality factor of resonator, $n_{\mathrm{B}}=$ Boltzmann factor for temperature dependence, $S=$ Total electron spin, $n_{\mathrm{s}}=$ Number of spins, $f\left(B_{1}, B_{\mathrm{m}}\right)=$ Spatial distribution of the microwave field and the modulation field, experienced by the sample. We calibrated this method using the stable radical TEMPOL and obtained a difference $<5 \%$ between the calculated and measured concentrations, confirming the reliability of the spin counting method. The absolute detection limit of number of spins in an EPR cavity $(\sim 20 \mu \mathrm{L})$ is estimated to be $\sim 1012$ spins, which translates to a detection limit of spin concentration of $\sim 100 \mathrm{nM}$ under our experimental conditions.

The error bars in $\mathrm{x}$-axis in Fig. 4 to 7 are based on uncertainties in SOA mass measurements in the balance. The same procedure was also applied to blank filters by immersing them into $10 \mathrm{mM}$ BMPO and $0.5 \mathrm{mM} \mathrm{Fe}^{2+}\left(\mathrm{FeSO}_{4} \cdot 7 \mathrm{H}_{2} \mathrm{O}, \geq 99 \%\right.$, Sigma Aldrich) solutions, confirming that very little BMPO or iron residues would stick to filters upon extraction. Extractions and EPR measurements were conducted under dark conditions to avoid interferences due to photolysis. $16 \mathrm{ml}$ glass vials with PTFE closure from VWR International GmbH were used. All the vials have been rinsed for 5-10 times with $10 \mathrm{~mL}$ fresh Milli-Q water each time and dried under ultrapure dry nitrogen gas $(99.999 \%$, Westfalen AG) before SOA extraction. Power free gloves (Carl Roth GmbH + Co.KG) and lab coat were used to avoid particles deposition from human body. Vials were used only once to avoid residue contaminations. Experiments were repeated with vials from different sets and there were no differences in the experimental results. In addition, the experimental results were fully consistent when the vials made from different materials (glass or polystyrene $15 \mathrm{ml}$ conical tubes (VWR 
International $\mathrm{GmbH})$ ) were used. Particle concentrations in the laboratory were less than $\sim 400 \mathrm{~m}^{-3}$ and we spent $<3$ s for opening and closing the vial caps to avoid contamination from deposition of particles into the samples. The filters were cleaned three times with 2-3 $\mathrm{mL}$ pure ethanol (ACS grade, VWR International S. A.S.) each time and dried with ultrapure dry nitrogen gas before SOA collection. The filter holder were cleaned with pure ethanol and Milli-Q water and dried with ultrapure dry nitrogen before experiment. $\mathrm{OH}$ radicals were not observed in different concentrations of hydrogen peroxide (TraceSELECT ${ }^{\circledR}$ Ultra, for ultratrace analysis) mixed with BMPO by an EPR. Thus, contaminations of transition metals during our handling procedure for particle extraction and analysis are negligible.

One example that includes the original and fitted spectra for $\mathrm{BMPO} /{ }^{\circ} \mathrm{OH}$ adduct of $\beta$-pinene SOA and cumene hydroperoxide is shown in Fig. S1. The final root mean square deviation of the fitting was $\sim 0.03$, indicating a very good agreement between the experimental and simulated spectra. Five different radicals (BMPO- $\mathrm{CH}_{3}$, t-BuO-BMPO, BMPO-OCH $\mathrm{H}_{3}$, and two isomers for BMPO-OH adduct) were found to coexist in tert-Butyl hydroperoxide solution. Good agreement between the fitted and measured spectrum confirms the dominance of $\mathrm{OH}$ radicals. The residual of the spectra can be regarded as trapped organic radicals.

Considering that the BMPO-OH adduct is stable over $\sim 30$ minutes, we have scanned samples over 50 times in $\sim 20$ min to elevate the signal to noise ratio of EPR spectra. The decay of DMPO-OH in water leads to uncertainty of $\sim 11 \%$ in quantification of trapped $\mathrm{OH}$ radicals. OH radicals in SOA water extracts were quantified using the spin counting method by removing interferences from organic radicals with the spin fitting method (see Methods and Fig. S1).

To investigate the role of water in the formation of $\mathrm{OH}$ radicals, ethanol (ACS grade, VWR International S. A.S.) was used as solvent. As shown in Fig. S5 c, BMPO-OH adducts were also observed in $\beta$-pinene SOA (E) and tert-Butyl hydroperoxide (F) in ethanol. These observations clearly show that $\mathrm{OH}$ radicals can be generated in the absence of water. Note that $\beta$-pinene SOA (Fig. 2B) and tert-Butyl hydroperoxide (Fig. 2G) yielded stronger $\mathrm{OH}$ signals in water compared to in ethanol. Additional experiments have shown that the $\mathrm{OH}$ formation efficiency of $\beta$-pinene SOA and tert-Butyl hydroperoxide in water increased by $\sim 30 \%$ at $310 \mathrm{~K}$ compared to at a room temperature of 
$295 \mathrm{~K}$. These results indicate that the source of $\mathrm{OH}$ radicals may be a combination of hydrolysis and thermal decomposition by organic hydroperoxides(Choe and Min, 2005).

Fig. S5 shows EPR spectra of mixtures of BMPO and cumene hydroperoxide (80\%, Sigma Aldrich) with and without $\mathrm{Fe}^{2+}$. The formation of $\mathrm{OH}$ and organic radicals upon decomposition of cumene hydroperoxide is clearly observed (A), which is substantially enhanced in the presence of $\mathrm{Fe}^{2+}$ due to Fenton-like reactions (B) (Chevallier., 2004). This is in agreement with previous observations of $\mathrm{OH}$ radicals generated by organic hydroperoxides in water (Guo et al., 2003). In contrast, no significant signals were observed for Di-tert-butyl peroxide solutions with and without $\mathrm{Fe}^{2+}$ (Fig. S5). These observations suggest that the source of $\mathrm{OH}$ radicals is organic hydroperoxides (ROOH), but not organic peroxides (ROOR).

\section{Kinetic Modelling}

The modelling result is in agreement with the experimental observations of trapping $\mathrm{OH}$ with the BMPO spin trap shown in Fig. $\mathrm{S} 2$ for $\mathrm{H}_{2} \mathrm{O}_{2}$. The aqueous phase chemistry is dominated by the reaction between $\mathrm{Fe}^{2+}$ and $\mathrm{H}_{2} \mathrm{O}_{2}$ (R8) and subsequent trapping of $\mathrm{OH}$ by $\mathrm{BMPO}$ (R14). The predominant loss channel for the BMPO-OH adduct is oxidation by $\mathrm{Fe}^{3+}(\mathrm{R} 17)$. The same strategy is applied for modelling the dissociation of organic hydroperoxides ( $\mathrm{ROOH})$ in the absence and presence of $\mathrm{Fe}^{2+}$ in extracts of secondary organic aerosol (SOA). We assume that the reactions (1), (8), (10) and (12) for $\mathrm{H}_{2} \mathrm{O}_{2}$ also apply for $\mathrm{ROOH}$ as reactions (19) - (22). Additionally, thermal decomposition of $\mathrm{ROOH}$ is included, which dominates dissociation and hence $\mathrm{OH}$ production in the absence of $\mathrm{Fe}^{2+}$ (Fig. 4a). Reaction with organic molecules ("SOA") is a significant loss pathway for $\mathrm{OH}$ in our experiments. Since the initial concentration of BMPO was the same for all experiments, the ratio of SOA and BMPO varies between the different experiments. Hence, at higher SOA concentrations (Fig. 4a), a larger fraction of $\mathrm{OH}$ will react with organic molecules instead of BMPO, leading to the observed non-linear increase of the BMPO-OH signal. In the presence of $\mathrm{Fe}^{2+}$, the Fenton-like reactions (19) and (20) lead to a much faster decomposition of ROOH. At higher $\mathrm{Fe}^{2+}$ concentrations however, the BMPO-OH adduct is effectively removed (Yamazaki and Piette, 1990) and the measured concentrations significantly reduced (Fig. 4b - d). Destruction of BMPO-OH can 
be viewed as iron-catalysed reactions, as $\mathrm{Fe}^{2+}$ is constantly recovered in the presence of peroxides. Hence, at high $\left[\mathrm{Fe}^{2+}\right] /[\mathrm{SOA}]$, destruction dominates over production. Such behaviour is more prominent for $\alpha$-pinene and $\beta$-pinene SOA, due to higher concentrations of organic hydroperoxides. For limonene SOA, the $\mathrm{OH}$ production increased rather gradually with lower abundance of organic hydroperoxides, leading in return to a less prominent destruction of the BMPO-OH adducts by $\mathrm{Fe}^{2+}$.

\section{OH production rate in clouds and lung lining fluid}

The $\mathrm{OH}$ production rate in cloud water due to Fenton reactions has been calculated. Typical dissolvable iron concentrations $\left(\mathrm{Fe}^{2+}\right.$ and $\mathrm{Fe}^{3+}$ with a molar ratio of $\left.1: 1\right)$ and $\mathrm{H}_{2} \mathrm{O}_{2}$ concentrations in clouds ('Typical cloud' in Fig. 7a) were set to be 0.1 to $2.5 \mu \mathrm{M}$ (Deguillaume et al., 2005) and 0.1 to $100 \mu \mathrm{M}$, respectively(Herrmann et al., 2015). A typical cloud water $\mathrm{pH}$ of 6 was assumed with a $k_{8}$ value of $1.1 \times 10^{-18} \mathrm{~cm}^{3} \mathrm{~s}^{-1}$ (Bataineh et al., 2012).

For estimation of the $\mathrm{OH}$ production rate in lung lining fluid by Fenton reactions, a typical iron concentration range of between 1 to $100 \mathrm{nM}$ was used with $\mathrm{Fe}^{2+}$ to $\mathrm{Fe}^{3+}$ molar ratio of 1:1 (Hunter et al., 2013). It should be noted that there is a background concentration of iron within the LLF but this is not included during calculations as these iron ions are associated with ferritin and therefore unavailable for Fenton reactions (Ghio et al., 2006; Ghio, 2009). Additionally, typical $\mathrm{H}_{2} \mathrm{O}_{2}$ concentrations range of 0.001 to $1 \mu \mathrm{M}$ in the LLF were chosen (Corradi et al., 2008). A pH value of 7 in the LLF (which is typical in healthy people (Paget-Brown et al., 2006)) was assumed and therefore $k_{8}$ in Table S1 would be expected to be $9.8 \times 10^{-18} \mathrm{~cm}^{3} \mathrm{~s}^{-1}$ (Bataineh et al., 2012), which lies within the range determined by global optimization.

In order to convert ambient concentration of $\mathrm{SOA}\left(\mu \mathrm{g} \mathrm{m}^{-3}\right)$ into an $\mathrm{OH}$ production rate in the LLF $\left(P_{\mathrm{OH}}, \mathrm{nM} \mathrm{s}^{-1}\right)$ the following equation was used: $P_{\mathrm{OH}}=($ Ambient SOA concentration $\times$ breathing rate $\times$ PM deposition rate $\left.\times R_{\mathrm{OH}}\right) /$ total LLF volume, where ambient SOA concentrations ranged from 1 to $100 \mu \mathrm{g} \mathrm{m}^{-3} . R_{\mathrm{OH}}$ is the $\mathrm{OH}$ formation efficiency of SOA in aqueous phase (Fig. 4). The breathing rate was assumed to be $230 \mathrm{~cm}^{3} \mathrm{~s}^{-1}$, the PM deposition rate was assumed to be $45 \%$ (Sarangapani and Wexler, 2000) and the total ELF volume was set to $25 \mathrm{ml}$ (Walters, 2002). 
Table S1. Equations and parameters used in the kinetic model.

\begin{tabular}{|c|c|c|c|}
\hline $\begin{array}{l}\text { Reaction } \\
\text { number }\end{array}$ & Equation & $\begin{array}{l}\text { Rate coefficient / } \\
\mathrm{cm}^{3} \mathrm{~s}^{-1}\end{array}$ & Reference \\
\hline 1 & $\mathrm{H}_{2} \mathrm{O}_{2}+\mathrm{OH} \rightarrow \mathrm{H}_{2} \mathrm{O}+\mathrm{HO}_{2}$ & $k_{1}=5.5 \times 10^{-14}$ & $\begin{array}{l}\text { Christensen, et } \\
\text { al.(Christensen et al., } \\
\text { 1982) }\end{array}$ \\
\hline 2 & $\mathrm{OH}+\mathrm{OH} \rightarrow \mathrm{H}_{2} \mathrm{O}_{2}$ & $k_{2}=8.6 \times 10^{-12}$ & $\begin{array}{l}\text { Sehested, et al.(Sehested } \\
\text { et al., 1968) }\end{array}$ \\
\hline 3 & $\mathrm{OH}+\mathrm{HO}_{2} \rightarrow \mathrm{H}_{2} \mathrm{O}+\mathrm{O}_{2}$ & $k_{3}=1.2 \times 10^{-11}$ & $\begin{array}{l}\text { Sehested, et al.(Sehested } \\
\text { et al., 1968) }\end{array}$ \\
\hline 4 & $\mathrm{HO}_{2}+\mathrm{HO}_{2} \rightarrow \mathrm{H}_{2} \mathrm{O}_{2}+\mathrm{O}_{2}$ & $k_{4}=1.4 \times 10^{-15}$ & $\begin{array}{l}\text { Rush and Bielski(Rush } \\
\text { and Bielski, 1985) }\end{array}$ \\
\hline 5 & $\mathrm{H}_{2} \mathrm{O}_{2}+\mathrm{HO}_{2} \rightarrow \mathrm{H}_{2} \mathrm{O}+\mathrm{O}_{2}+\mathrm{OH}$ & $k_{5}=5.0 \times 10^{-21}$ & Koppenol et al. (1978) \\
\hline 6 & $\mathrm{HO}_{2}+\mathrm{O}_{2}^{-} \rightarrow \mathrm{H}_{2} \mathrm{O}_{2}+\mathrm{OH}^{-}+\mathrm{O}_{2}$ & $k_{6}=1.6 \times 10^{-13}$ & $\begin{array}{l}\text { Rush and Bielski(Rush } \\
\text { and Bielski, 1985) }\end{array}$ \\
\hline 7 & $\mathrm{H}^{+}+\mathrm{O}_{2}^{-} \rightarrow \mathrm{HO}_{2}$ & $k_{7}=8.0 \times 10^{-11}$ & $\begin{array}{l}\text { Divišek and } \\
\text { Kastening(Divišek and } \\
\text { Kastening, 1975) }\end{array}$ \\
\hline 8 & $\mathrm{Fe}^{2+}+\mathrm{H}_{2} \mathrm{O}_{2} \rightarrow \mathrm{Fe}^{3+}+\mathrm{OH}^{-}+\mathrm{OH}$ & $k_{8}=1.0-6.0 \times 10^{-17}$ & \\
\hline 9 & $\mathrm{Fe}^{2+}+\mathrm{OH} \rightarrow \mathrm{Fe}^{3+}+\mathrm{OH}^{-}$ & $k_{9}=0.01-1.0 \times 10^{-11}$ & $\begin{array}{l}\text { Stuglik and } \\
\text { Zagorski(Stuglik and } \\
\text { PawełZagórski, 1981) }\end{array}$ \\
\hline 10 & $\mathrm{Fe}^{3+}+\mathrm{H}_{2} \mathrm{O}_{2} \rightarrow \mathrm{Fe}^{2+}+\mathrm{HO}_{2}+\mathrm{H}^{+}$ & $k_{10}<1.0 \times 10^{-20}$ & \\
\hline 11 & $\mathrm{Fe}^{3+}+\mathrm{HO}_{2} \rightarrow \mathrm{Fe}^{2+}+\mathrm{O}_{2}+\mathrm{H}^{+}$ & $k_{11}=3.3 \times 10^{-18}$ & $\begin{array}{l}\text { Rush and Bielski(Rush } \\
\text { and Bielski, 1985) }\end{array}$ \\
\hline 12 & $\mathrm{Fe}^{2+}+\mathrm{H}_{2} \mathrm{O}_{2} \rightarrow \mathrm{Fe}^{4+} \mathrm{O}^{2+}+\mathrm{H}_{2} \mathrm{O}$ & $k_{12}=0.5-8 \times 10^{-17}$ & \\
\hline 13 & $\mathrm{Fe}^{4+}+\mathrm{Fe}^{2+} \rightarrow 2 \mathrm{Fe}^{3+}$ & $k_{13}=10^{-19}-10^{-16}$ & \\
\hline 14 & $\mathrm{BMPO}+\mathrm{OH} \rightarrow \mathrm{BMPO}-\mathrm{OH}$ & $k_{14}=0.06-6.0 \times 10^{-12}$ & \\
\hline 15 & BMPO-OH $\rightarrow$ Product & $k_{15}=0.02-2.0 \times 10^{-4}$ & \\
\hline
\end{tabular}




\begin{tabular}{lll}
\hline 16 & $\mathrm{BMPO}-\mathrm{OH}+\mathrm{Fe}^{2+} \rightarrow$ Product $+\mathrm{Fe}^{3+}$ & $k_{16}=0.1-1.0 \times 10^{-19}$ \\
17 & $\mathrm{BMPO}-\mathrm{OH}+\mathrm{Fe}^{3+} \rightarrow{\text { Product }+\mathrm{Fe}^{2+}}$ & $k_{17}<1.0 \times 10^{-20}$ \\
18 & $\mathrm{BMPO}-\mathrm{OH}+\mathrm{Fe}^{4+} \rightarrow{\text { Product }+\mathrm{Fe}^{3+}}$ & $k_{18}=1-8.0 \times 10^{-18}$ \\
19 & $\mathrm{Fe}^{2+}+\mathrm{ROOH} \rightarrow \mathrm{Fe}^{3+}+\mathrm{RO}^{-}+\mathrm{OH}$ & $k_{19}=k_{8}$ \\
20 & $\mathrm{Fe}^{2+}+\mathrm{ROOH} \rightarrow \mathrm{Fe}^{3+}+\mathrm{RO}^{-}+\mathrm{OH}^{-}$ & $k_{20}<1.0 \times 10^{-20}$ \\
21 & $\mathrm{Fe}^{3+}+\mathrm{ROOH} \rightarrow \mathrm{Fe}^{2+}+\mathrm{RO}_{2}+\mathrm{H}^{+}$ & $k_{21}=k_{10}$ \\
22 & $\mathrm{OH}+\mathrm{ROOH} \rightarrow \mathrm{ROH}^{+\mathrm{HO}_{2}}$ & $k_{22}=k_{1}$ \\
23 & $\mathrm{ROOH} \rightarrow \mathrm{RO}+\mathrm{OH}$ & $k_{23}=0.1-4 \times 10^{-5}$ \\
24 & $\mathrm{SOA}+\mathrm{OH} \rightarrow \mathrm{SOA}^{\prime}$ & $k_{24}=0.3-2.0 \times 10^{-12}$ \\
25 & $\mathrm{BMPO}-\mathrm{OH}+\mathrm{OH} \rightarrow$ Product & $k_{25}=0.1-8.0 \times 10^{-12}$ \\
\hline
\end{tabular}


(a)

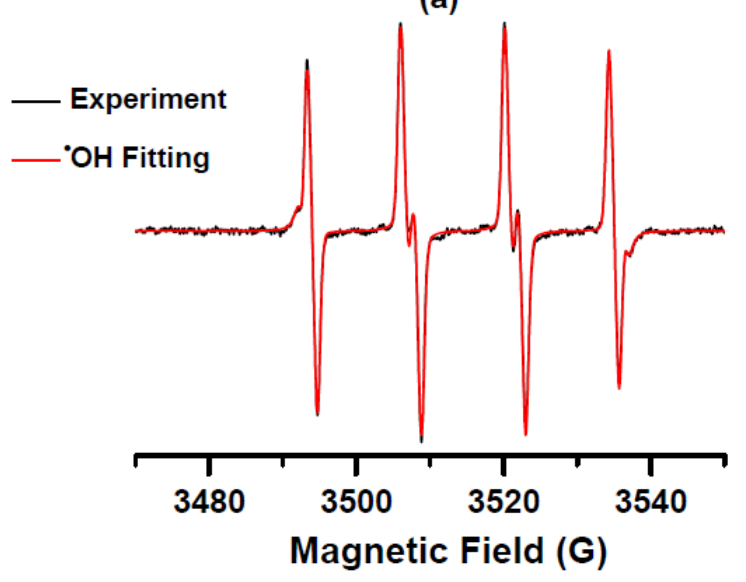

(b)

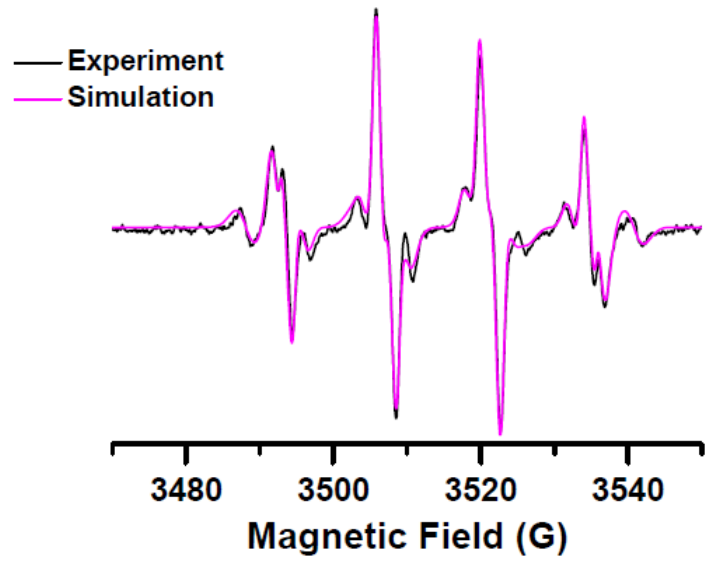

Figure S1. Measured, fitted and simulated EPR spectra. (a) Measured (black) and fitted (red) EPR spectra of water extracts of $\beta$-pinene SOA mixed with BMPO. (b) Measured (black) and simulated (pink) EPR spectra of a solution of tert-Butyl hydroperoxide mixed with BMPO. 


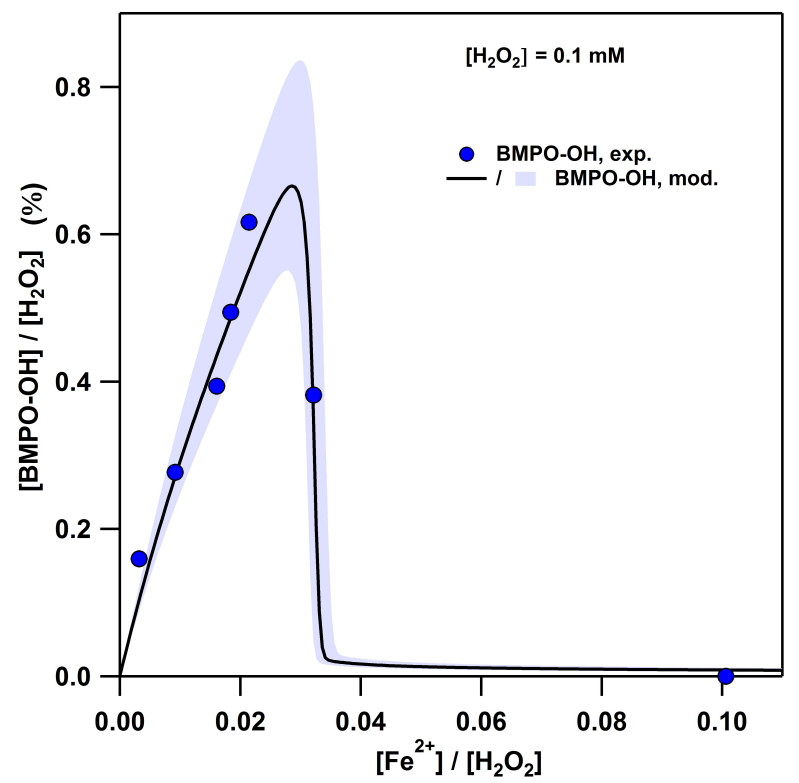

Figure S2. OH formation efficiency in $\mathrm{H}_{2} \mathrm{O}_{2} / \mathrm{Fe}^{2+}$ solutions. The concentrations of $\mathrm{H}_{2} \mathrm{O}_{2}$ and BMPO were $0.1 \mathrm{mM}$ and $10 \mathrm{mM}$, respectively. The solid curve with shaded area is modelled with uncertainty. 


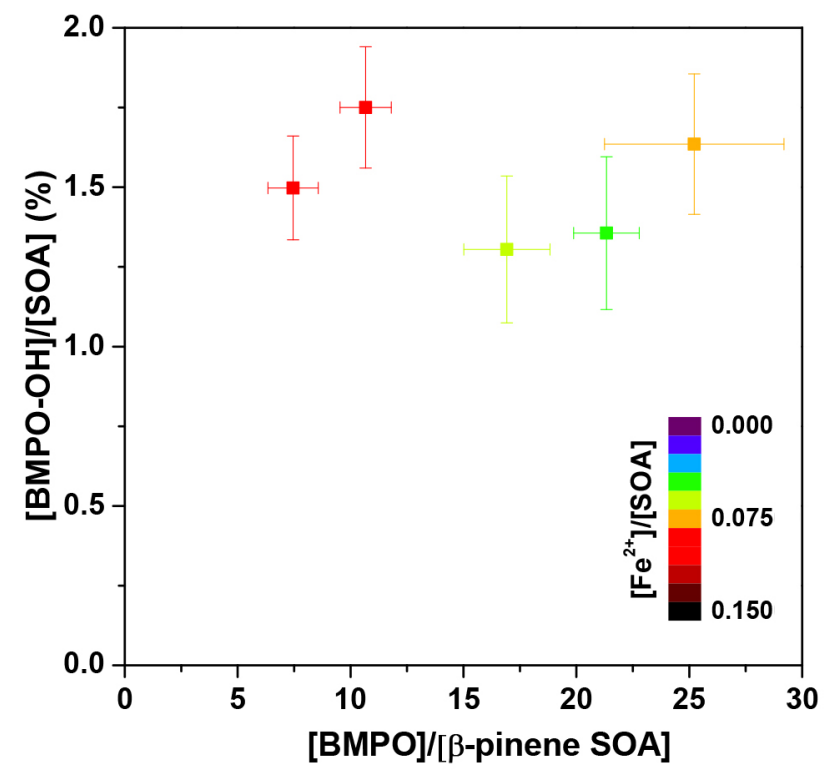

Figure S3. OH formation efficiency of $\beta$-pinene $\mathrm{SOA} / \mathrm{Fe}^{2+}$ solutions as a function of BMPO concentration. The markers are colour coded with the molar ration of $\mathrm{Fe}^{2+}$ to $\mathrm{SOA}$ ([BMPO-OH]/[ $\beta-$ pinene $\mathrm{SOA}])$. 


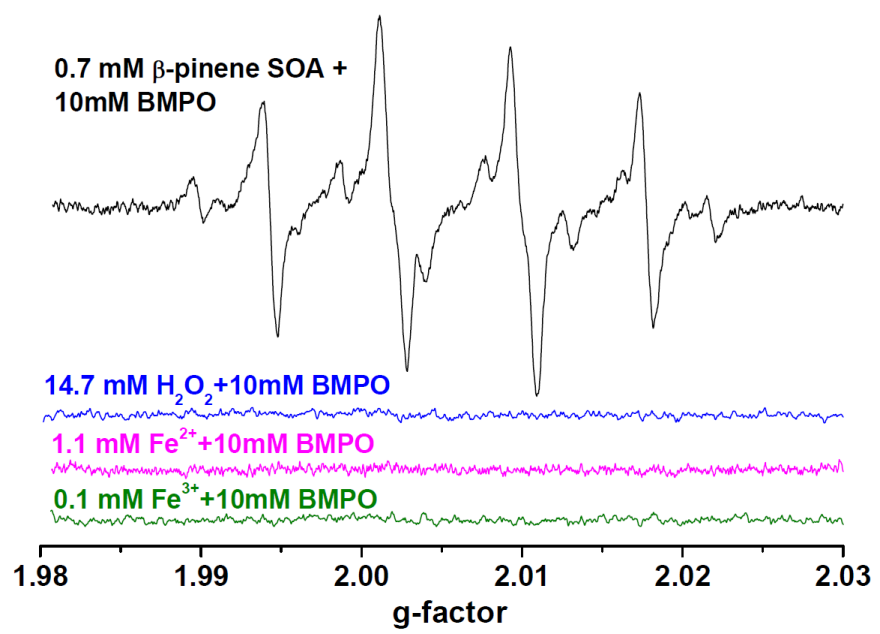

Figure S4. EPR spectra of BMPO mixtures. BMPO adducts with a $0.7 \mathrm{mM} \beta$-pinene SOA extracts (black line). Blank spectra of BMPO mixed with $14.7 \mathrm{mM} \mathrm{H}_{2} \mathrm{O}_{2}$ (blue line), $1.1 \mathrm{mM} \mathrm{Fe}^{2+}$ (pink line), and $0.1 \mathrm{mM} \mathrm{Fe}^{3+}$ (olive line) solutions. The BMPO concentration is $10 \mathrm{mM}$ for all the samples. 
(a)

Cumene hydroperoxide

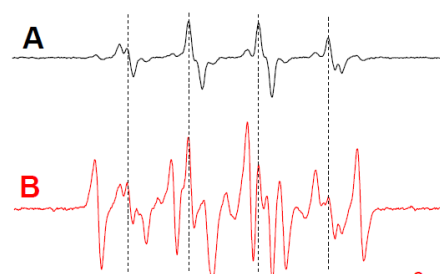

Cumene hydroperoxide/ $\mathrm{Fe}^{2+}$ (b)

Di-tert-Butyl peroxide

D

\begin{tabular}{ccc}
\multicolumn{3}{c}{ Di-tert-Butyl peroxide/Fe ${ }^{2+}$} \\
\cline { 2 - 2 } & 2.00 & 2.02 \\
& \multicolumn{2}{c|}{ g-factor }
\end{tabular}

(c)

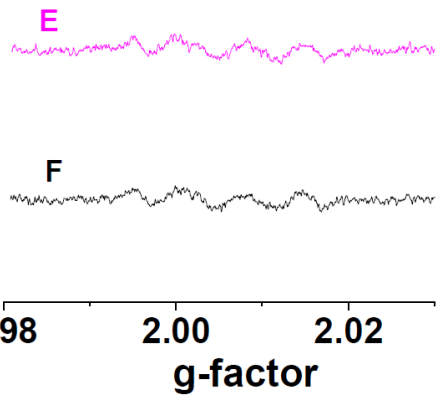

Figure S5. EPR spectra of various samples. EPR spectra of $15 \mathrm{mM}$ cumene hydroperoxide solution in the absence of $\mathrm{Fe}^{2+}(\mathrm{A})$ and in the presence of $1.5 \mathrm{mM} \mathrm{Fe}^{2+}$ (B). EPR spectra of $15 \mathrm{mM}$ Di-tertButyl peroxide solution in the absence of $\mathrm{Fe}^{2+}(\mathrm{C})$ and in the presence of $1.5 \mathrm{mM} \mathrm{Fe}^{2+}$. EPR spectra of $\beta$-pinene SOA (E) and tert-Butyl hydroperoxide (F) in ethanol. 


\section{Supplementary references.}

Bataineh, H., Pestovsky, O., and Bakac, A.: pH-induced mechanistic changeover from hydroxyl radicals to iron (IV) in the Fenton reaction, Chem. Sci., 3, 1594-1599, 2012.

Chevallier., E.: "Fenton-like" reactions of methylhydroperoxide and ethylhydroperoxide with Fe2+ in liquid aerosols under tropospheric conditions, Atmos. Environ., 38, 921, 2004.

Choe, E., and Min, D. B.: Chemistry and reactions of reactive oxygen species in foods, J. Food. Sci., 70, R142-R159, 2005.

Christensen, H., Sehested, K., and Corfitzen, H.: Reactions of hydroxyl radicals with hydrogen peroxide at ambient and elevated temperatures, J. Phys. Chem., 86, 1588-1590, 1982.

Corradi, M., Pignatti, P., Brunetti, G., Goldoni, M., Caglieri, A., Nava, S., Moscato, G., and Balbi, B.: Comparison between exhaled and bronchoalveolar lavage levels of hydrogen peroxide in patients with diffuse interstitial lung diseases, Acta Biomed, 79, 73-78, 2008.

Deguillaume, L., Leriche, M., Desboeufs, K., Mailhot, G., George, C., and Chaumerliac, N.: Transition Metals in Atmospheric Liquid Phases: Sources, Reactivity, and Sensitive Parameters, Chem. Rev., 105, 3388-3431, 2005.

Divišek, J., and Kastening, B.: Electrochemical generation and reactivity of the superoxide ion in aqueous solutions, J. Electroanal. Chem., 65, 603-621, 1975.

Eaton, G. R., Eaton, S. S., Barr, D. P., and Weber, R. T.: Quantitative EPR, Springer Science \& Business Media, 2010.

Ghio, A. J., Turi, J. L., Yang, F., Garrick, L. M., and Garrick, M. D.: Iron homeostasis in the lung, Biol. Res., 39, 67-77, 2006.

Ghio, A. J.: Disruption of iron homeostasis and lung disease, Biochimica et Biophysica Acta (BBA) - General Subjects, 1790, 731-739, 2009.

Guo, Q., Qian, S. Y., and Mason, R. P.: Separation and identification of DMPO adducts of oxygencentered radicals formed from organic hydroperoxides by HPLC-ESR, ESI-MS and MS/MS, J. Am. Soc. Mass Spectrom., 14, 862-871, 2003.

Herrmann, H., Schaefer, T., Tilgner, A., Styler, S. A., Weller, C., Teich, M., and Otto, T.: Tropospheric Aqueous-Phase Chemistry: Kinetics, Mechanisms, and Its Coupling to a Changing Gas Phase, Chem. Rev., 115, 4259-4334, 2015.

Hunter, R. C., Asfour, F., Dingemans, J., Osuna, B. L., Samad, T., Malfroot, A., Cornelis, P., and Newman, D. K.: Ferrous iron is a significant component of bioavailable iron in cystic fibrosis airways, MBio, 4, e00557-00513, 2013.

Koppenol, W. H., Butler, J., and Leeuwen, J. W. v.: The Haber - Weiss cycle, Photochem. Photobiol., 28, 655-658, 1978.

Paget-Brown, A. O., Ngaintrakulpanit, L., Smith, A., Bunyan, D., Hom, S., Nguyen, A., and Hunt, J. F.: Normative data for pH of exhaled breath condensate, Chest, 129, 426-430, 2006.

Rush, J. D., and Bielski, B. H. J.: Pulse radiolytic studies of the reaction of perhydroxyl/superoxide $\mathrm{O}_{2}{ }^{-}$with iron(II)/iron(III) ions. The reactivity of $\mathrm{HO}_{2} / \mathrm{O}_{2}{ }^{-}$with ferric ions and its implication on the occurrence of the Haber-Weiss reaction, J. Phys. Chem., 89, 5062-5066, 1985. 
Sarangapani, R., and Wexler, A. S.: The role of dispersion in particle deposition in human airways, Toxicol. Sci., 54, 229-236, 2000.

Sehested, K., Rasmussen, O. L., and Fricke, H.: Rate constants of $\mathrm{OH}$ with $\mathrm{HO}_{2}, \mathrm{O}_{2}^{-}$, and $\mathrm{H}_{2} \mathrm{O}_{2}{ }^{+}$from hydrogen peroxide formation in pulse-irradiated oxygenated water, J. Phys. Chem., 72, 626-631, 1968.

Stuglik, Z., and PawełZagórski, Z.: Pulse radiolysis of neutral iron (II) solutions: oxidation of ferrous ions by OH radicals, Radiat. Phys. Chem., 17, 229-233, 1981.

Walters, D. V.: Lung lining liquid-The hidden depths, Neonatology, 81, 2-5, 2002.

Weber, R. T.: Xenon Data Processing Reference 2012.

Yamazaki, I., and Piette, L. H.: ESR spin-trapping studies on the reaction of $\mathrm{Fe}^{2+}$ ions with $\mathrm{H}_{2} \mathrm{O}_{2}$ reactive species in oxygen toxicity in biology, J. Biol. Chem., 265, 13589-13594, 1990. 